\title{
Preparation of Nano-Crystalline Manganese-Zinc Ferrite with Arabic Gum by Network Gel Method
}

\author{
Ping Wan
}

Jingdezhen Ceramic Institute, Jingdezhen, 333001

\section{Keywords: Manganese-zinc ferrite; Network gel; Arabic gum}

\begin{abstract}
The preparation of nano-crystalline manganese-zinc ferrite was affected by the $\mathrm{pH}$ value greatly in the network gel method and the optimum $\mathrm{pH}$ value was the range of 9 11. Monophase manganese-zinc ferrite without impurity phase could be obtained via adding additive after sintering at low temperature. The crystalline size of manganese-zinc ferrite powder was reduced to $7 \mathrm{~nm}$ from $50 \mathrm{~nm}$ after sintering at $800^{\circ} \mathrm{C}$ for $2 \mathrm{~h}$ as the arabic gum concentration increasing from $5 \mathrm{wt} \%$ to $20 \mathrm{wt} \%$. Different crystalline sizes of the manganese-zinc ferrite were obtained under using different arabic gum concentration.
\end{abstract}

\section{Introduction}

Soft ferrite material refers to complex oxides composed of iron and other one or more kinds of metal oxides, mainly MnZn ferrite and NiZn ferrite two series, nano-MnZn ferrite not only has the advantages of low loss, high permeability, high operating frequency, high resistivity, etc., and has a quantum size effect, small size effect, surface and interface effects, has become the key point in the field of magnetic materials [1-5]. The preparation of nanometer soft ferrite material can be divided into solid phase method, liquid phase method and gas phase method. Some of these methods can obtain finer powder, but needing complex synthetic routes, the requirements to equipment are high, difficult to carry out large-scale production; some need a higher heat treatment temperature, which will often cause the evaporation of $\mathrm{Zn}^{2+}$. In order to obtain co-precipitates with easy and uniform distribution, nanocrystalline $\mathrm{Mn}-\mathrm{Zn}$ ferrite was prepared by gelatin gel method in this study. The metal ions were fixed in a gel grid with three-dimensional structure for precipitation to produce precursors, so that the reaction happened in a limited space to prevent aggregation and agglomeration in the precipitation process, not only the dispersion was better than the traditional precipitation method, but also the nano-particles have smaller particle size, is an effective improvement to the traditional precipitation method.

\section{Experimental Part}

Preparation of Powder. According to the proportion of manganese zinc ferrite, the appropriate amount of ferrous nitrate, manganese nitrate, zinc nitrate are weighed and put in $500 \mathrm{ml}$ beaker. Add $300 \mathrm{ml}$ of deionized water into the beaker, dissolve in $70{ }^{\circ} \mathrm{C}$ water bath, add a certain amount of Arabic gum and additives to make it fully mixed evenly, and then under the stirring and ultrasonic state, uniformly dropping $\mathrm{NH}_{4} \mathrm{HCO}_{3}-\mathrm{NH}_{4} \mathrm{OH}$ Solution, using the $\mathrm{pH}$ meter to detect $\mathrm{pH}$ value of solution, when the $\mathrm{pH}$ reached a predetermined value, and then maintained for 10 hours and then cooled to room temperature. The resulting homogeneous gel was cut into small pieces and dried at $90{ }^{\circ} \mathrm{C}$ for 12 hours using an electric blast oven. Finally, The MnZn ferrite powder can be obtained by calcining at a temperature of $10{ }^{\circ} \mathrm{C} / \mathrm{min}$ at a certain temperature (for example, $800{ }^{\circ} \mathrm{C}$ ) for $2 \mathrm{~h}$.

Characterization of Powder. The powder was analyzed by Bruker AXS D8-Advance X-ray diffractometer (XRD) for the phase. The microstructure of the samples was observed by JSM-6700F field emission electron microscopy.

\section{Results and Discussion}

As the Arabian gum is interconnected to form a space grid, and the grid was filled with the 
dispersion medium, so that the system lost the liquidity to be jelly. The Arabic gum can dissolved in an aqueous solution containing $\mathrm{Zn}^{2+}, \mathrm{Fe}^{2+}$ and $\mathrm{Mn}^{2+}$, and the gel is changed by changing the temperature. The ferrite particle size is closely related to the formation of precipitated precursors, the finer the particle size of the precursor, and the smaller the grain size of the final product. The lower the solubility of product, the smaller the precursor particle size. $\left(\mathrm{Fe}(\mathrm{OH})_{3} \mathrm{Ksp}=4.0 \times 10-38\right)$ is much lower than that of ferrous hydroxide $\left(\mathrm{Fe}(\mathrm{OH})_{2} \mathrm{Ksp}=8.0 \times 10-16\right)$, and the corresponding particle size of ferric hydroxide is much smaller than that of ferrous hydroxide.

The $\mathrm{pH}$ value has the decisive effect on the final form of each sediment, and the $\mathrm{pH}$ value is too high or too low will affect the complete precipitation of $\mathrm{Mn}^{2+}, \mathrm{Zn}^{2+}$ and $\mathrm{Fe}^{2+}$. The XRD patterns of $\mathrm{MnZn}$ ferrite formed by calcination at $800{ }^{\circ} \mathrm{C}$ for $2 \mathrm{~h}$ at different $\mathrm{pH}$ values are shown in Fig. 1.

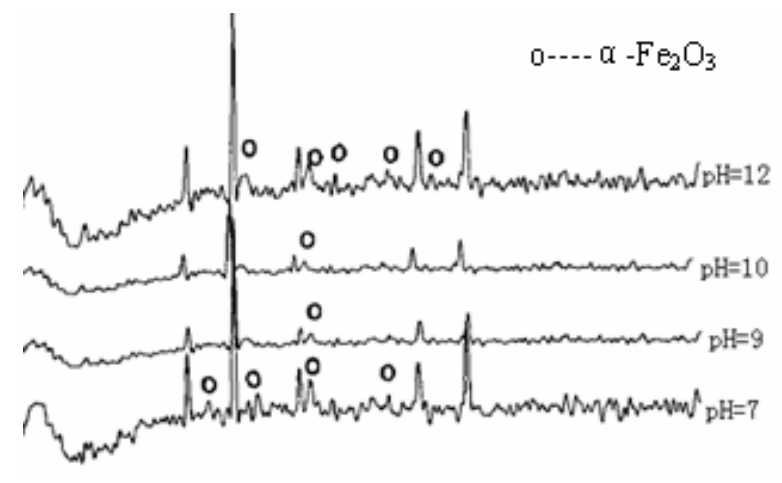

Figure 1. XRD pattern of the manganese-zinc ferrite at different $\mathrm{pH}$

Fig. 1 shows that at $\mathrm{pH} \mathrm{7,9,10,12,} \mathrm{the} \mathrm{manganese} \mathrm{zinc} \mathrm{ferrite} \mathrm{with} \mathrm{pure} \mathrm{phase} \mathrm{could} \mathrm{be}$ synthesized, but the maximum $\mathrm{pH}$ can not exceed 12 . When $\mathrm{pH}$ values were at 7 and $12, \alpha-\mathrm{Fe} 2 \mathrm{O} 3$ hetero-phase appears and the $\mathrm{pH}$ should be maintained at 9-11 during coprecipitation. The XRD spectra of the xerogel samples and the calcined samples obtained at the $\mathrm{pH}$ value of 9 and the gelatin concentration of $10 \mathrm{wt} \%$ at different temperatures showed that the xerogels were amorphous. When the calcination temperature is $400{ }^{\circ} \mathrm{C}$, the (220), (311), (400) and (440) crystal faces of the sample begin to show a weak absorption peak with incomplete crystallization. When the temperature is $500{ }^{\circ} \mathrm{C}$, the diffraction peak is enhanced, when the temperature reached $600{ }^{\circ} \mathrm{C}$, the obtained product was the same as the diffraction peak of standard $\mathrm{Mn}^{2+}{ }_{0.5} \mathrm{Zn}_{0.5} \mathrm{Fe}_{2} \mathrm{O}_{4}$, and it was confirmed that it was $\mathrm{MnZn}$ ferrite $\left(\mathrm{Mn}^{2+}{ }_{0.5} \mathrm{Zn}_{0.5} \mathrm{Fe}_{2} \mathrm{O}_{4}\right)$ with cubic spinel structure. When the calcination temperature rises to $800{ }^{\circ} \mathrm{C}$, the position of each peak in the XRD pattern does not change greatly. However, the diffraction peak of all the crystal faces becomes sharp and the relative intensity increases, which indicates that the crystal form of the crystal tends to complete. At the same time, $\alpha-\mathrm{Fe}_{2} \mathrm{O}_{3}$ hetero phase was observed. According to the Scherer formula $\mathrm{D}=\mathrm{k} \lambda / \beta \cos \theta$, where $\mathrm{k}=0.89, \lambda=0.154 \mathrm{~nm}, \beta$ is the half width, $\theta$ is the diffraction angle, and under the same ingredient, The average particle size of the manganese zinc ferrite obtained by calcination at 600 , 700 and $800^{\circ} \mathrm{C}$ is $17 \mathrm{~nm}, 31 \mathrm{~nm}$ and $42 \mathrm{~nm}$, respectively. The size of MnZn ferrite nanocrystalline particles is strongly dependent on the heat treatment temperature. With the increase of heat treatment temperature, the grain grows to bigger one. The higher the calcination temperature, the small grain will gradually spread, growing up to bigger grain, resulting in the increase of average grain size gradually .

The Effect of Additives. As the coprecipitated precursor is composed of $\mathrm{Fe}(\mathrm{OH})_{2}, \mathrm{Fe}(\mathrm{OH})_{3}, \mathrm{Ni}$ $(\mathrm{OH})_{2}, \mathrm{Zn}(\mathrm{OH})_{2}$ and other particles. In the process of forming the MnZn ferrite, MnZn ferrite is easily obtained on the surface where the precursor particles are in contact with each other, but at the same time, heterogeneous phases such as $\mathrm{Fe}_{2} \mathrm{O}_{3}$ and $\mathrm{Fe}_{3} \mathrm{O}_{4}$ are generated. Although the diffusion of ions between these grains migrates need to overcome the binding of the crystal field forces, a higher activation transfer energy is required and leads to higher reaction temperatures. But in fact only by increasing the reaction temperature and prolong the reaction time can not make each other completely diffuse and form a single phase $\mathrm{MnZn}$ ferrite. Therefore it is necessary to add additives 
during the co-precipitation process to promote simultaneous precipitation of the various ions so that the various ions are homogeneously mixed at the atomic or molecular scale as possible to obtain a uniform coprecipitated precursor, so that the heterogeneous phase disappears at a lower calcination temperature and yields a single phase product. The results of the XRD test of the sample obtained by calcining the coprecipitated precursor at $800^{\circ} \mathrm{C}$ for $2 \mathrm{~h}$ with the addition of the additive are shown in Fig.2. Fig. 2 shows that the impurity may disappear by adding the additive.

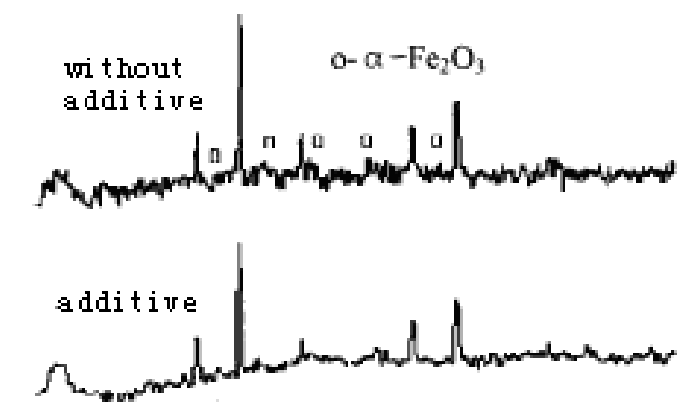

Figure 2. XRD patterns of two powders with additive and without additive

The SEM image of the product obtained by calcining the sample prepared at $800{ }^{\circ} \mathrm{C}$ for $2 \mathrm{~h}$ at the $\mathrm{pH}$ of 9 and a gelatin concentration of $10 \mathrm{wt} \%$ was added as an additive and without an additive.
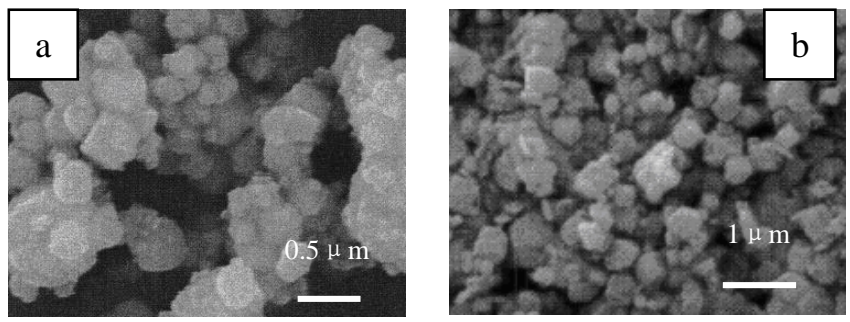

Figure 3. SEM photograph of the powders synthesized with additive and without additive

From Fig. 3 and XRD analysis, it can be seen that the sample prepared without additive is shown in Fig. 3 (a). The product obtained after adding the additive having mixed phase and agglomeration is shown in Fig. 3 (b), the complete crystallinity, and the particle size distribution is 11-32nm for product obtained by adding additives to help reduce or eliminate agglomeration, can get better dispersion of manganese zinc ferrite powder. Through adding of additives can lower or weaken degree of agglomeration or The single phase MnZn ferrite powder with no heterogeneous phase can be obtained, good crystallinity and narrow particle size distribution can be prepared by adding additives.

The Effect of Arabic Gum Concentration on the Grain of the Product. The network structure size of the Arabic gum is intrinsically related to the Arabic gum concentration. The large Arabic gum concentration and small gel structure gap, is conducive to get smaller grain. The effect of Arabic gum concentration on grain is shown in Figure 4. When the amount of Arabic gum increased from $5 \mathrm{wt} \%$ to $20 \mathrm{wt} \%$, the grain size of the final product (at $800{ }^{\circ} \mathrm{C}$ for $2 \mathrm{~h}$ ) decreased from $50 \mathrm{~nm}$ to $7 \mathrm{~nm}$, which indicated that the size of the gel structure could play a decisive role in the size of the product. The crystallite size of MnZn ferrite is regulated by changing the concentration of Arabic gum. 


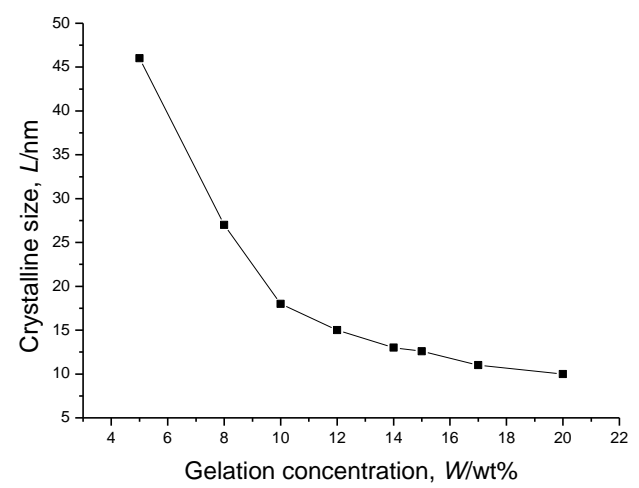

Figure 4. Effect of Arabic gum concentration on crystalline size

\section{Conclusion}

The nanocrystalline MnZn ferrite was prepared by Arabic gum method, and the metal ions were fixed in a gel grid with a three-dimensional structure to precipitate a precursor. The reaction was carried out in a limited space to prevent the agglomeration of precipitate in the process of precipitation. The $\mathrm{pH}$ value has a decisive effect on the final morphology of each precipitate, and the optimum $\mathrm{pH}$ range is from 9 to 11 . The addition of the additive during the coprecipitation process allows the heterogeneous phase to disappear at a lower calcination temperature and then obtain a single phase manganese zinc ferrite product. The size of the gel structure has a decisive effect on the size of the product. When the amount of Arabic gum is increased from $5 \mathrm{wt} \%$ to 20 $\mathrm{wt} \%$, the particle size of the final product (at $800{ }^{\circ} \mathrm{C}$ for $2 \mathrm{~h}$ ) is reduced from $50 \mathrm{~nm}$ to $7 \mathrm{~nm}$. We can adjust the size of MnZn ferrite crystallites by the method of changing the concentration of Arabic gum.

\section{References}

[1] M.B. Tian. Magnetic materials [M] . Beijing: Tsinghua University Press, 2001.

[2] Gilbert I P, Moorthy V, Bull S J, et al. Development of soft magnetic composites for low-loss applications [J], Journal of Magnetism and Magnetic Materials, 2002, 242-245 (1): 232 234.

[3] B.P. Zhang, M.T. Tang, S.H. Yang, et al. Liquid phase synthesis research progress of manganese zinc soft ferrite powder [J]. China Manganese Industry, 2004, 22 (1): $33 \sim 40$.

[4] S.H. Yang, C.B. Tang, M.T. Tang, et al. Preparation of $\mathrm{Mn}-\mathrm{Zn}$ soft ferrite powder by direct-coprecipitation method with lower power [J]. Metallurgical Engineering, 2004, 24 (2): 61 $\sim 64$.

[5] Moulin J, Champion Y, Greneche J M, et al. Magnetic properties of MnZn ferrite with ultra-fine grain structure [J]. Journal of Magnetism and Magnetic Materials, 2006, 254-255: 538 540.

Author: Wan Ping, (1984.8-), female, engineer, research direction: ceramic materials 